\title{
Colloidal transport and deposition through dense vegetation
}

\author{
Congrong Yu ${ }^{\text {a, }{ }^{* *}}$, Peiyi Duan ${ }^{\mathrm{a}}$, D.A. Barry ${ }^{\mathrm{b}, *}$, William P. Johnson ${ }^{\mathrm{c}}$, Li Chen ${ }^{\mathrm{a}, \mathrm{d}}$, Zhongbo Yu ${ }^{\mathrm{a}}$, \\ Yufeng Sun ${ }^{\mathrm{a}}$, Ying $\mathrm{Li}^{\mathrm{a}}$ \\ ${ }^{a}$ State Key Laboratory of Hydrology-Water Resources and Hydraulic Engineering, Hohai University, College of Hydrology and Water Resources, Nanjing, Jiangsu, \\ 210098, China \\ ${ }^{\mathrm{b}}$ Ecological Engineering Laboratory (ECOL), Institute of Environmental Engineering (IIE), Faculty of Architecture, Civil and Environmental Engineering (ENAC), Ecole \\ Polytechnique Fédérale de Lausanne (EPFL), 1015, Lausanne, Switzerland \\ ${ }^{\mathrm{c}}$ Department of Geology \& Geophysics, University of Utah, Salt Lake City, UT, 84112, USA \\ ${ }^{\mathrm{d}}$ Division of Hydrologic Sciences, Desert Research Institute, Las Vegas, NV, USA
}

\section{H I G H L I G H T S}

- Colloid deposition rate decreased with travel distance following an approximate power law under various flow conditions.

- Gravity contributed to the decrease, but could not explain its magnitude.

- Mechanisms driving decreased deposition rate coefficient in granular media may also apply to submerged vegetation.

\section{A R T I C L E I N F O}

Handling Editor: Michael Bank

\section{Keywords:}

Colloids

Vegetation

Deposition rate coefficient

Travel distance

Physical and chemical conditions

DLVO

Advection

Dispersion

First-order kinetics
G R A P H I C A L A B S T R A C T

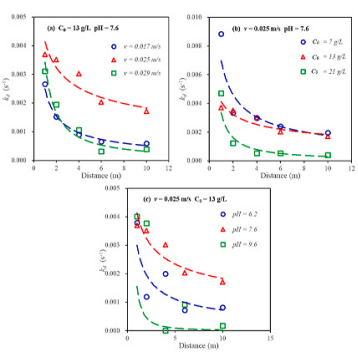

\begin{abstract}
A B S T R A C T
The effectiveness of submerged synthetic aquatic vegetation on removal of colloids from flowing water was investigated to explore retention of particulate nonpoint source pollutants in aquatic systems. In colloid transport experiments, the deposition rate coefficient of colloids in dense vegetation is often taken as spatially constant. This assumption was tested by experiments and modeling aimed at quantifying changes in colloid retention with travel distance in submerged synthetic aquatic vegetation. Experiments were performed in a 10-m long, 0.6-m wide flume with a 5-cm water depth under different fluid velocities, initial colloid concentrations, and solution $\mathrm{pH}$ values. A model accounting for advection, dispersion and first-order kinetic deposition described the experimental data. The colloid deposition rate coefficient showed a power-law decrease with travel distance, and reached a steady state value before the end of the flume. Measured changes in colloid properties with transport distance ( $\zeta$ potential and size) could not explain the observed decrease. While gravity was shown to contribute to the decrease, its impact was too weak to explain the decreasing power law trend, suggesting that processes operating in granular media to produce similar outcomes may also apply to submerged vegetation.
\end{abstract}

\footnotetext{
* Corresponding author.

$* *$ Corresponding author.

E-mail addresses: cryu@hhu.edu.cn (C. Yu), andrew.barry@epfl.ch (D.A. Barry).
} 


\section{Introduction}

Removal of colloidal particles (e.g., $0.1-10 \mu \mathrm{m}$ ) by dense vegetation is critical to non-point source (NPS) pollution control. Bio-colloids like bacteria, viruses and protozoa (Hickey and Doran, 2004; Magette et al., 1989) are potential contaminants, whereas non-biological colloids such as clays or microplastics (Barry et al., 2013; Jin et al., 2019) can influence the fate of chemical pollutants such as radionuclides (Koelsch et al., 2006; Tomer et al., 2003), pesticides (Wang and Wang, 2008) and heavy metals (Bin et al., 2011), due to their high specific surface area.

Colloid capture by vegetation is an important mechanism for removing colloids from surface water (Palmer et al., 2004), more so if the vegetation is dense (Davies et al., 2004; Olilo et al., 2016; Palmer et al., 2004; Wu et al., 2014; Yu et al., 2012). Whereas extensive literature exists regarding colloid removal in saturated porous media (Bradford et al., 2003, 2013; Chen et al., 2015; Gao et al., 2004; Molnar et al., 2015; Phenrat et al., 2010; Saiers and Ryan, 2005; Wang et al., 2016), relatively sparse information exists for removal in submerged vegetation. In both porous media (Kretzschmar et al., 1997; Molnar et al., 2015; Jin et al., 2018) and submerged vegetation (Wu et al., 2012; Yu et al., 2012, 2019), colloid removal mechanisms are often assessed using classic filtration theory, a key parameter of which is the deposition rate coefficient, $k_{d}$.

In saturated porous media, $k_{d}$ can under some conditions be spatially constant (Albarran et al., 2014; Chen et al., 2015; Li et al., 2004; Syngouna and Chrysikopoulos, 2013), although both laboratory and field experiments demonstrate that $k_{d}$ can decrease (or otherwise vary) with distance from the source (Molnar et al., 2015; Schijven and Simunek, 2002; Tufenkji et al., 2003; Wang et al., 2014). This spatial variability is attributed to colloid size and surface charge variations (Chatterjee et al., 2011; Foppen et al., 2007; Molnar et al., 2015; Tong and Johnson, 2007). For example, an increased negative $\zeta$ (zeta) potential (repulsion) of mobile colloids with increased transport distance was observed in a laboratory glass bead column experiment (Tufenkji and Elimelech, 2005). Alternatively, Tong and Johnson (2007) reasoned that colloids with lower $\zeta$ potential can undergo increased secondary energy minimum retention, producing faster- and slower-attaching subpopulations. Colloid size variation also produces variations in $k_{d}$ among the colloid population and therefore with transport distance, for example because of the preferential removal of larger individual colloids (Chatterjee et al., 2011) leading to decreasing $k_{d}$ with increased transport distance. Spatial variations of $k_{d}$ are commonly observed even in the absence of variations in colloid size or surface properties, leading to the hypothesis that such behavior results from fundamental processes operating during transport in porous media. Johnson (2020) proposed that $k_{d}$ changes with transport distance due to the existence of a fast-attaching colloid population that is not replenished due to incomplete pore-scale mixing. As the fast-attaching subpopulation is progressively depleted with increased transport distance, the subpopulation of non-fast-attaching colloids proportionally increases, in which case the overall $k_{d}$ correspondingly decreases.

Evidence for a similar conclusion for colloidal transport through dense vegetation is not available. This work considers flow through dense vegetation, which can be considered as a large-porosity porous medium. However, compared with laminar flow in granular media, the flow hydrodynamics in dense vegetation are more complex since the fluid velocity is much larger than in granular media. Because of the large porosity and higher flow velocity, Reynolds numbers for flow through vegetation will generally far exceed those for porous media, which will impact on deposition of transported colloids. It is this situation that this paper considers, in particular how $k_{d}$ changes with transport distance.

A distance of at least $10 \mathrm{~m}$ of dense vegetation is recommended for removal of colloidal contaminants (Reichenberger et al., 2007; Syversen and Bechamann, 2004). In contrast, studies colloid removal by vegetation typically involve small-scale experiments on the order of several centimeters (Wu et al., 2011, 2012, 2014, Yu et al., 2012, 2013), for which $k_{d}$ is constant. Upscaling from small experiments is thus feasible only if $k_{d}$ is spatially constant. Therefore, it is of practical significance to investigate whether the $k_{d}$ for colloid removal by vegetation is spatially constant over relevant transport distances. Consequently, the objectives of this study are as follows: (1) to determine the empirical relationship between the deposition rate $k_{d}$ and travel distance in submerged aquatic vegetation, and (2) to explore the dominant mechanism(s) that governs this empirical relationship as elucidated by varying physical and chemical conditions.

\section{Material and methods}

\subsection{Materials}

Powdered kaolinite (Tianjin Fuchen Chemical Reagents Factory, China) was thoroughly mixed in deionized water at three concentrations by adding 40,80 or $120 \mathrm{~g}$ to $2 \mathrm{~L}$ of tap water (4 mM ionic strength). Mixing was achieved by vigorous shaking with an ultrasonic bath for 30 min, after which the mixtures were left to stand for $7 \mathrm{~h}$. The colloids remaining in suspension were then siphoned into a flask for use in the experiments. The colloid concentration was determined with an ultraviolet spectrophotometer at a wavelength of $350 \mathrm{~nm}$. The colloid size range was $900-1200 \mathrm{~nm}$ (mode $\sim 1100 \mathrm{~nm}$ ) measured by light scattering (Malvern Zetasizer Nano ZS90). Potassium nitrate at a concentration of $307 \mathrm{ppm}$ was used in the experiment as a conservative tracer. Plastic turf grass (in blocks of 0.4-m length and 0.6-m width, grass height of $8 \mathrm{~cm}$ ) was selected as the experimental vegetation (Fig. 1). The vegetation density was 1029 (uniformly positioned) stems $/ \mathrm{m}^{2}$. The colloid and vegetation $\zeta$ potentials were determined using a Malvern Zetasizer Nano ZS90. For the vegetation $\zeta$ potential, three plastic turf grasses were soaked in deionized water and then sonicated for $3 \mathrm{~h}$. Then, the $\zeta$ potential of the particles leaving the plastic surface by sonication represents the vegetation $\zeta$ potential (ZetaPlus instrument, Brookhaven Instrument Co., Holtsville, NY).

\subsection{Colloid transport experiments}

The colloid transport experiments were conducted in a $12 \mathrm{~m} \times 0.6 \mathrm{~m}$ $\times 0.2 \mathrm{~m}$ open flume that contained a layer of plastic turf grass (Fig. 1). A pump was used to produce a specified constant-rate inflow. A rectifying tube was used to stabilize inflow in the first $1 \mathrm{~m}$ of the flume, while a plastic board located at the end of the flume controlled the water depth. The experiments had a flow depth of $5 \mathrm{~cm}$ (i.e., less than the grass height of $8 \mathrm{~cm}$ ). The colloid and tracer were injected as a pulse at the flume's inlet.

Inflow with colloid-free water was first applied to the flume for about $30 \mathrm{~min}$ from a $3-\mathrm{m}^{3}$ tank, allowing the flume system to reach a steady flow condition. One liter of colloid and potassium nitrate mixture was then injected into the flume inlet as a pulse injection ( $0 \mathrm{~m}$ in Fig. $1 \mathrm{a})$. Surface water samples were collected at 1, 2, 4, 6 and $10 \mathrm{~m}$ from the injection point at different sampling intervals (from 10 to $120 \mathrm{~s}$ ), with three samples collected across each longitudinal distance for $11 \mathrm{~min}$. An ultraviolet spectrophotometer was used to determine nitrate and colloid concentrations in the samples at wavelengths of 220 and $350 \mathrm{~nm}$, respectively. Triplicate samples at each distance were averaged. In addition, the $\zeta$ potential and the average size of the colloids were measured with a Malvern Zetasizer Nano ZS90. For each condition (see next section), the transport experiment was repeated three times.

\subsection{Experimental conditions}

The experimental conditions were designed to examine the effects of fluid velocity, initial colloid concentration and $\mathrm{pH}$ on retention of colloids in dense vegetation. The fluid velocity was controlled by a pump (Fig. 1a), while the $\mathrm{pH}$ (measured) in the $3-\mathrm{m}^{3}$ tank was adjusted using a $\mathrm{NaOH} / \mathrm{HCl}$ mixture. The experimental conditions are listed in Table 1. 
(a)

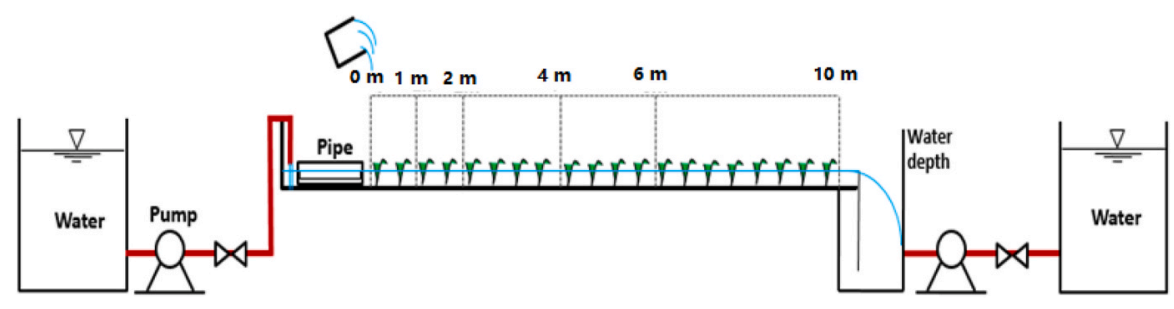

(b)

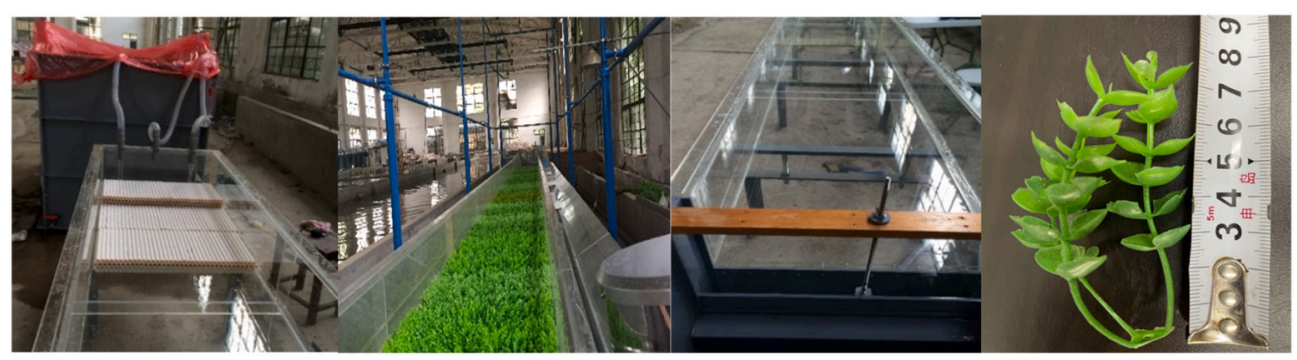

Fig. 1. Laboratory experiment: (a) schematic of the experimental setup, including the flow system, colloid addition location $(0 \mathrm{~m})$, and sampling locations at $1,2,4$, 6 and $10 \mathrm{~m}$ downstream. (b) From left to right the panels show: rectifying tube system used to stabilize the inflow in the first $1 \mathrm{~m}$ of the flume; dense, plastic turf grass in the flume; water-depth controller board at the end of the flume; close up image of leaf and stem layer of the vegetation.

Table 1

Experimental conditions and power law fit of the deposition rate coefficient $k_{d}$ as a function of travel distance $x$ for different cases.

\begin{tabular}{|c|c|c|c|c|c|c|c|c|}
\hline ID & Flow rate $(\mathrm{m} / \mathrm{s})$ & Depth $(\mathrm{cm})$ & Initial colloid concentration $(\mathrm{g} / \mathrm{L})$ & $\mathrm{pH}$ & Ionic strength $(\mathrm{mmol} / \mathrm{L})$ & Power law fit for $k_{d}(/ \mathrm{s})$ & $\mathrm{R}^{2}$ & $p$-value \\
\hline I.1 & 0.017 & 5 & 13 & 7.6 & 4 & $0.002 x^{-0.682}$ & 0.967 & 0.002 \\
\hline I. 2 & 0.025 & 5 & 13 & 7.6 & 4 & $0.004 x^{-0.352}$ & 0.827 & 0.021 \\
\hline I.3 & 0.029 & 5 & 13 & 7.6 & 4 & $0.003 x^{-1.036}$ & 0.858 & 0.015 \\
\hline II.1 & 0.025 & 5 & 7 & 7.6 & 4 & $0.007 x^{-0.598}$ & 0.830 & 0.020 \\
\hline II. 2 & 0.025 & 5 & 13 & 7.6 & 4 & $0.004 x^{-0.353}$ & 0.827 & 0.021 \\
\hline II.3 & 0.025 & 5 & 21 & 7.6 & 4 & $0.003 x^{-1.049}$ & 0.863 & 0.014 \\
\hline III.1 & 0.025 & 5 & 13 & 6.2 & 4 & $0.003 x^{-0.617}$ & 0.563 & 0.089 \\
\hline III. 2 & 0.025 & 5 & 13 & 7.6 & 4 & $0.004 x^{-0.352}$ & 0.827 & 0.021 \\
\hline III. 3 & 0.025 & 5 & 13 & 9.6 & 4 & $j^{\S}$ & / & / \\
\hline
\end{tabular}

$\S$ The relationship between $k_{d}$ and travel distance $x$ did not follow a power law, indicated $\mathrm{b}$.

\subsection{Transport model}

The transport of colloids in submerged dense vegetation was described using the advection-dispersion equation with deposition kinetics (Kretzschmar et al., 1997):

$\frac{\partial C}{\partial t}=D \frac{\partial^{2} C}{\partial x^{2}}-v \frac{\partial C}{\partial x}-k_{d} C$

where $C$ is the liquid phase concentration $\left[\mathrm{M} / \mathrm{L}^{3}\right], t$ is time $[\mathrm{T}], D$ is the diffusion/dispersion coefficient $\left[\mathrm{L}^{2} / \mathrm{T}\right], x$ is distance $[\mathrm{L}], v$ is the average flow velocity in the dense vegetation $[\mathrm{L} / \mathrm{T}]$ and $k_{d}[/ \mathrm{T}]$ is the first-order colloid deposition rate coefficient.

STANMOD (https://www.ars.usda.gov/pacific-west-area/riversideca/agricultural-water-efficiency-and-salinity-research-unit/docs/mod el/stanmod-model/, last accessed 20 July 2021), was used to solve Eq. (1) numerically for zero initial concentrations, a pulse-input inflow, and zero-concentration-gradient boundary condition at the outflow. In the model, the average fluid velocity $v$ was determined using the arrival time of the tracer breakthrough peak concentration at each section. The model was first applied to simulate the transport of the tracer to determine $D$, which was then used to simulate the transport of colloids to determine $k_{d}$ under different conditions.

\subsection{Colloid filtration and DLVO theory}

In colloid filtration theory, the collector efficiency $(\eta)$ is the ratio of the number of colloids that contact the collector (vegetation) to the number of colloids introduced to the collector. The collector efficiency was upscaled to $k_{d}$ following Johnson and Hilpert (2013):

$k_{d}=-\ln (1-\eta) \frac{N_{c}}{L} v$

where (Nelson and Ginn, 2011):

$\frac{N_{c}}{L}=\frac{(1-\theta)^{1 / 3}}{2 d_{c}}$

where $d_{c}$ is the grain diameter and $\theta$ is the volumetric water content, equivalent to porosity under saturated conditions. Also, $v$ is the pore fluid velocity, $\eta$ is collector efficiency, $N_{c}$ is a series of collectors and $L$ is the total length of those collectors, assuming each collector has the same $\eta$ value.

This parameter $\eta$ includes gravitational, diffusion, and interception components of $\eta\left(\eta_{G}, \eta_{D}\right.$, and $\eta_{I}$, respectively). They are determined by mechanistic trajectory simulations performed using Traj-Hap module of Parti-Suite (https://wpjohnsongroup.utah.edu/trajectoryCodes, last 
accessed 21 July 2021) according to colloid filtration theory. The TrajHap module of Parti-Suite simulates particle trajectories and surface interactions and is suitable for investigating mechanistic nano-to microparticle transport since it is based on pore-scale Lagrangian trajectory simulations with hydrodynamic retardation correction and torquebalance analysis (Johnson, 2020). To reduce computational intensity, particle trajectory simulations were initiated only within the so-called limiting radius, which is the radius from the axis of flow beyond which colloids will not intercept the grain surface. The colloid population that would have entered the collector beyond the limiting radius was not simulated, but was accounted for in calculation of the collector efficiency $(\eta)$. An important factor in the Traj-Hap module is the limiting colloid injection radius (denoted $R_{\text {lim }}$ in Parti-Suite). In Parti-Suite's computation of particle trajectories, $R_{\text {lim }}$ controls the capture distance beyond which a given particle will not be intercepted by a surface. If used in simulations was confirmed to be sufficiently large to ensure those colloids that would exist outside the limiting radius, but colloids that are inside the radius correspond to the collector (not simulated) and would not attach (Fig. SI7). The porosity of the water column with submerged vegetation was determined by fluid displacement measurements to be 0.96 , from which the radius of the Happel sphere-in-cell collector $\left(R_{\text {lim }}\right)$ was determined as $0.5 \mathrm{~mm}$. Although the vegetation and colloids were both negatively charged, we simulated colloids as positively charged (favorable condition), i.e., the charge of colloid and collector have opposite signs in order to evaluate the impact of physical mass transfer processes (interception, diffusion, and settling).

The extended Derjaguin-Landau-Verwey-Overbeek (xDLVO) theory (Derjaguin and Landau, 1993; Verwey, 1947) was used to determine colloid-collector interaction forces: van der Waals (Nir and Anderson, 1977; Gregory 1981), electric double layer (Lin and Wiesner, 2012) and Lewis acid-base (Wood and Rehmann, 2014). Extended DLVO interactions were calculated using the xDLVO module of Parti-Suite. In this paper, the Hamaker constant is $4.28 \times 10^{-20} \mathrm{~J}$, and the acid-based energy was set to $-2.7 \times 10^{-10} \mathrm{~J} / \mathrm{m}^{2}$ (Yu et al., 2020).

\section{Results}

\subsection{Experimental and simulated colloid and nitrate breakthrough curves}

The observed and simulated breakthrough-elution concentration histories (BTCs) of nitrate and kaolinite with an average velocity of $0.029 \mathrm{~m} / \mathrm{s}$, initial concentration of $21 \mathrm{~g} / \mathrm{L}, \mathrm{pH}$ of 6.2 and ionic strength (IS) of $0.1 \mathrm{mmol} / \mathrm{L}$ are shown in Fig. 2 (other observed and simulated BTCs are in the Supporting Information, SI). All BTCs for nitrate and kaolinite are reasonably symmetrical although some tailing is evident. The curves show the expected broadening and lowering of the peak
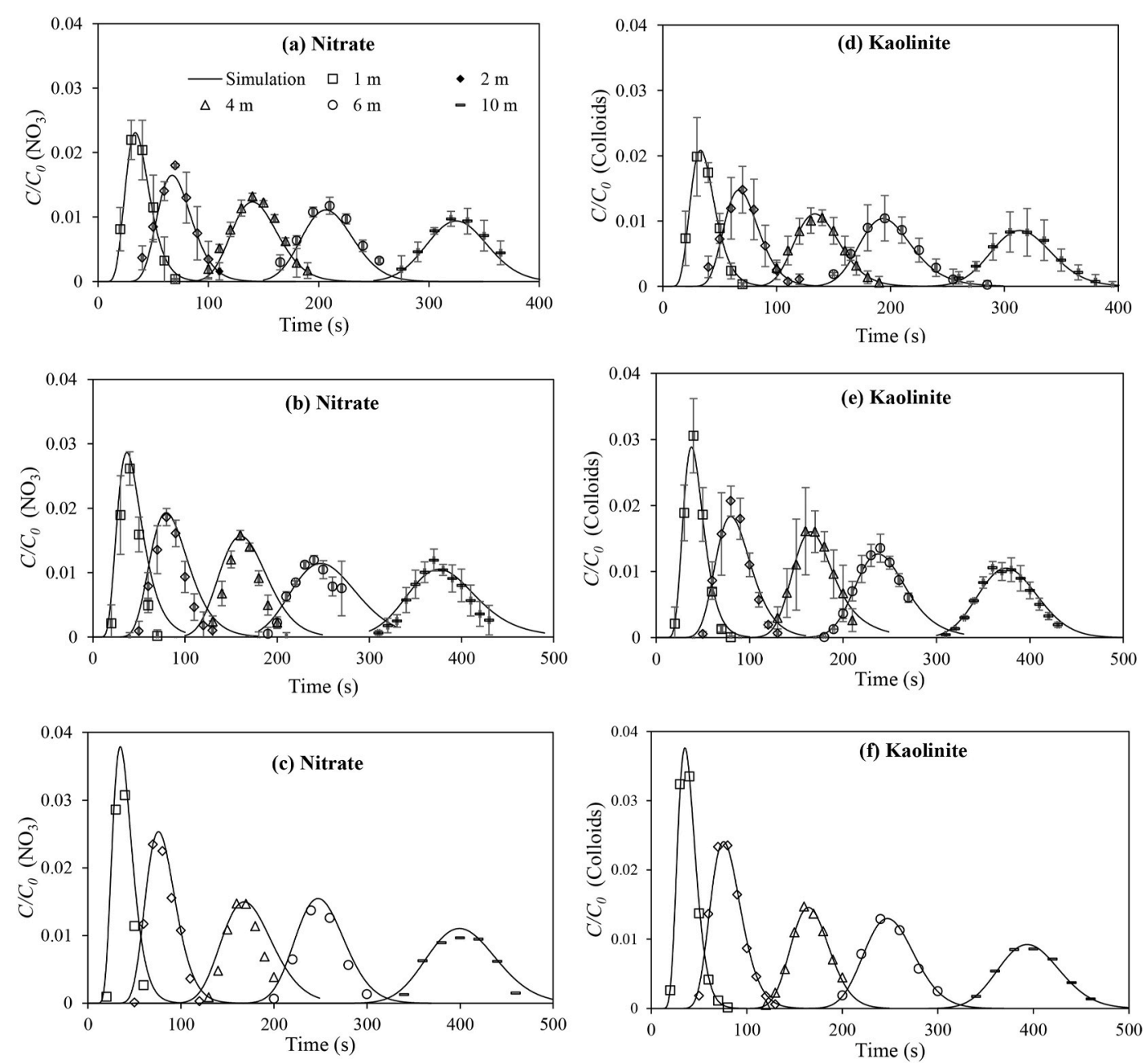

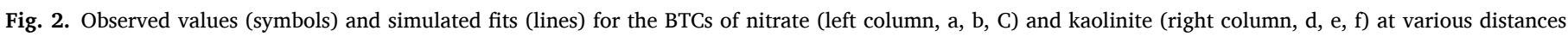

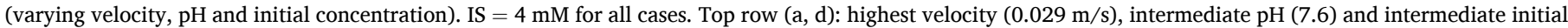

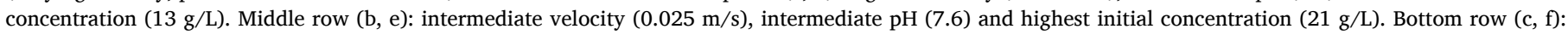

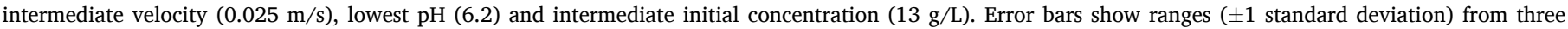
replicate experiments. No replicates in (c) and (f). 
concentration with increased travel distance, due to dispersion and deposition. Simulations using STANMOD described the transport of nitrate and kaolinite well with a single dispersion coefficient $\left(\mathrm{R}^{2}>0.9\right.$ for all fits) along with a spatially decreasing deposition rate coefficient $\left(k_{d}\right)$, as discussed below.

\subsection{Colloid deposition rate coefficient decreased with transport distance}

The fitted $k_{d}$ for kaolinite decreased nonlinearly (power law) with travel distance for all experiments (Fig. 3, Table 1), a result that is consistent with colloid transport in granular media under conditions where colloid-surface repulsion is significant (Tong and Johnson, 2007; Chatterjee et al., 2010; Johnson, 2020).

For all conditions of varied velocity, initial concentration, and $\mathrm{pH}, k_{d}$ decreased with transport distance in the submerged vegetation (Fig. 3). The impact of fluid velocity on $k_{d}$ was non-monotonic, with the highest initial $k_{d}$ value being associated with the intermediate velocity $(0.025$ $\mathrm{m} / \mathrm{s}$ ) (Fig. 3a). The initial value of $k_{d}$ decreased modestly as the initial concentration increased (Fig. 3b), indicating that a limited number of attachment sites may exist. Blocking (attached colloids preventing further colloid attachment) is a possible mechanism for this behavior. However, no blocking term was required to describe the BTCs (Eq. (1)), indicating that attachment sites were not exhausted, and the change in $k_{d}$ with change in initial concentration is modest (i.e., factor of two); therefore, we do not emphasize this trend herein. The initial (upstream) value of $k_{d}$ was equivalent among the three $\mathrm{pH}$ values, whereas the decrease with transport distance was least for the intermediate $\mathrm{pH}(\mathrm{pH}$ =7.62) (Fig. 3c), although the reason for this outcome is not clear.

\subsection{Colloid $\zeta$ potential and size distribution with travel distance}

The influence of transport distance on parameters critical to kaolinite deposition ( $\zeta$ potential and colloid size) were examined to determine whether their potential spatial variation explains the observed decrease in $k_{d}$ with transport distance. The $\zeta$ potential of recovered colloids became more negative (from approximately -11 to $-18 \mathrm{mV}$ ) across the length of the flume for the highest pH (9.55) (Fig. 4a). However, for the two lower $\mathrm{pH}$ conditions, the $\zeta$ potential became less negative (from approximately -16 to $-11 \mathrm{mV}$ ) across the length of the flume. The increased negative $\zeta$ potential for the higher $\mathrm{pH}$ potentially contribute to the observed decrease of $k_{d}$ with increased transport distance. However, as the colloid radius increased from 1.26 to $1.43 \mu \mathrm{m}$, the second minimum energy barrier to deposition decreased (Fig. SI8). The fact that all $\mathrm{pH}$ conditions showed a similar power law decrease in $k_{d}$ with transport distance demonstrates that changes in the kaolinite $\zeta$ potential during transport cannot explain the observed decreases in $k_{d}$.

Colloid size increased modestly $(20 \%)$ with transport distance under the highest $\mathrm{pH}$ condition (9.6), whereas colloid size increased negligibly with transport distance for the two lower $\mathrm{pH}$ conditions (Fig. 4b). The factor two-to-three increase in colloid size at the highest $\mathrm{pH}$ is unexplained. The impact of colloid size on $k_{d}$ under favorable conditions was examined using Parti-Suite, which demonstrated a modest increase (approximately 10\%) with colloid size increase from 2500 to $3000 \mathrm{~nm}$ across the flume distance. Therefore, the modest increase in colloid size with transport distance cannot explain the observed $k_{d}$ decrease.

The combined impacts of colloid $\zeta$ potential and size changes with distance on the calculated barrier to deposition either showed no trend

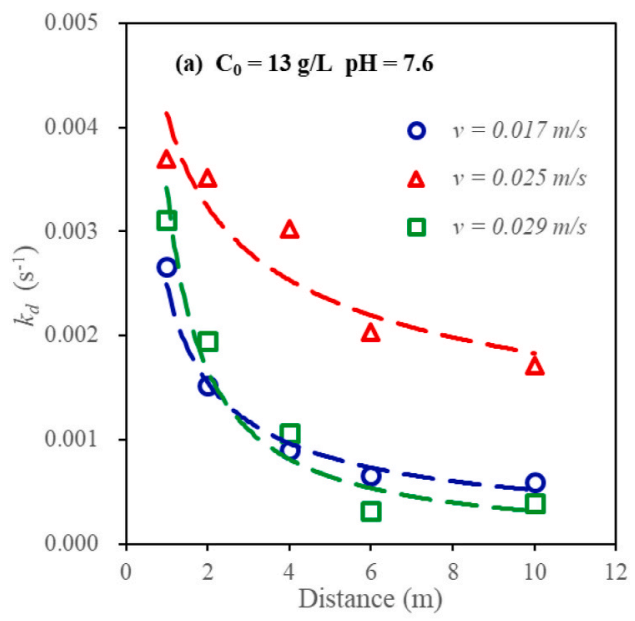

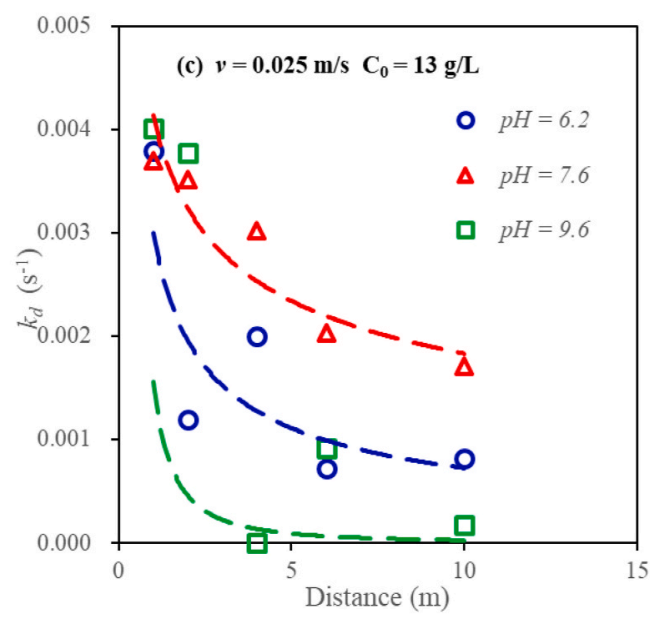

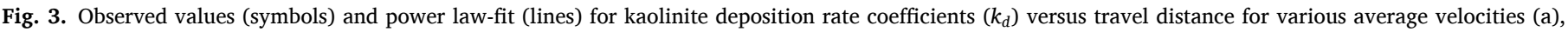
initial kaolin concentrations (b) and $\mathrm{pH}$ values (c). For all experiments IS $=4 \mathrm{mM}$. 

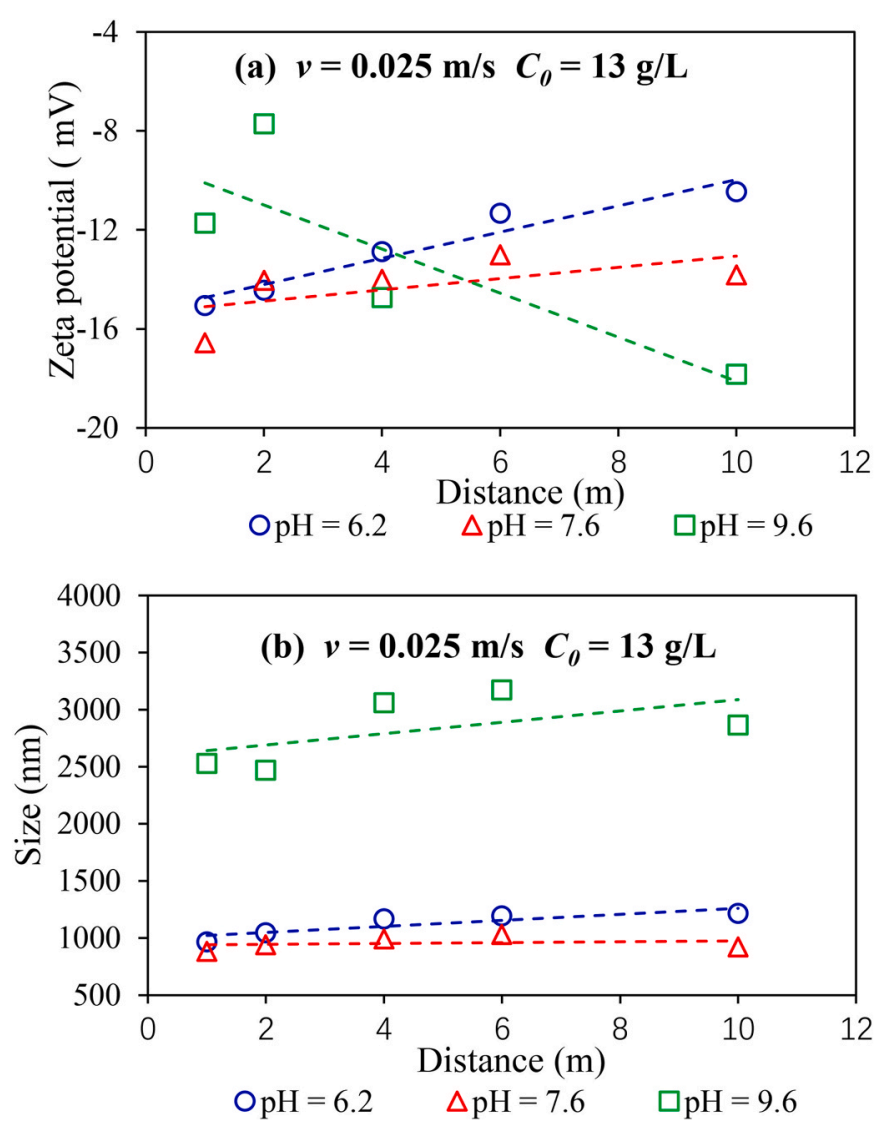

Fig. 4. $\zeta$ potential (a) and average diameter (b) of colloids versus transport distance for different $\mathrm{pH}$ values. For all experiments IS $=4 \mathrm{mM}$. Points are values from experiments and dashed lines are linear regressions.

(pH 9.6), or the barrier decreased with increased transport distance for the two remaining $\mathrm{pH}$ conditions (Fig. SI9), further demonstrating that these parameters cannot explain the consistently observed $k_{d}$ decrease with increased transport distance.

\section{Discussion}

\subsection{Velocity impact on colloid deposition}

The non-monotonic impact of fluid velocity on $k_{d}$ was examined using the Traj-Hap module of Parti-Suite under favorable conditions. A grain radius of $0.5 \mathrm{~mm}$ produced simulated values of $\eta$ and $k_{d}$ of the same order of magnitude as those that were experimentally observed (Table SI5). The gravitational, diffusion, and interception-only components of $\eta\left(\eta_{G}, \eta_{D}\right.$, and $\eta_{I}$, respectively) were determined by setting to zero diffusion, gravity, or both forces in the mechanistic trajectory (Parti-Suite) simulations. The simulations indicated that as the fluid velocity increased from 0.017 to $0.029 \mathrm{~m} / \mathrm{s}, \eta_{G}$ increased then decreased dramatically, and $\eta_{I}$ did so modestly (Fig. 5), likely contributing to the experimentally-observed modest nonmonotonic trend of the initial $k_{d}$ values as a function of velocity (Fig. 3a). In contrast, the decrease in $k_{d}$ with increased velocity observed in another vegetation experiment (Purich, 2006) was tentatively attributed to flow vortices. While Reynolds numbers in the flume experiments (approximately 100-200) were in the range of laminar flow, the possibility of impact from vortices cannot be ruled out. However, no measurements are available to address this question.

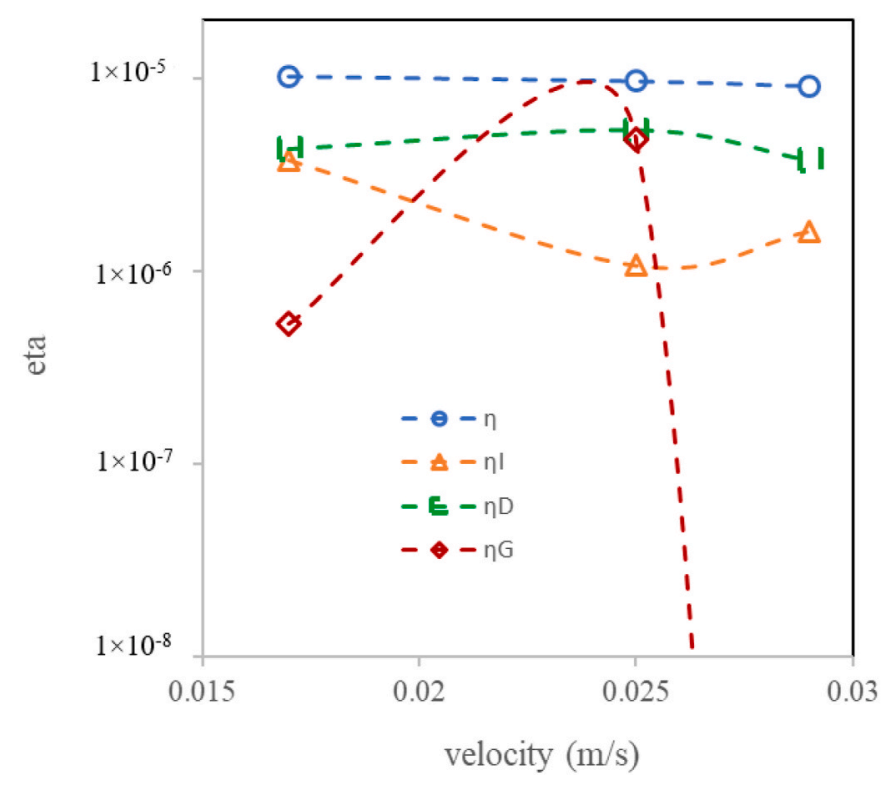

Fig. 5. $\eta, \eta_{I}, \eta_{D}$, and $\eta_{G}$ as a function of fluid velocity, as determined from mechanistic trajectory simulations with parameters provided in Table S6.

\subsection{Causes of the observed decrease in $k_{d}$ with increased transport distance}

The $\zeta$ potential and colloid size cannot explain the observed decrease in $k_{d}$ with increased transport distance. However, due to the high surface area of the leaf layer relative to the stem layer, we expect the $k_{d}$ values to be far lower for stems relative to leaves by some factor that we denote $f$. Because of gravity the number of colloids in the stem layer would increase with transport distance, thus the $k_{d}$ would decrease with transport distance. We explored the possibility that gravity impacted $k_{d}$ as a function of transport distance by moving colloids from the vegetation leaf layer (top half of water column) to the stem layer (bottom half of water column) (Fig. 1).

The mass change in the water column is equal to the product of the overall filtration rate coefficient $\left(k_{d, \text { overall }}\right)$, the overall water column concentration $\left(C_{\text {overall }}\right)$, and the overall water column volume ( $\left.V_{\text {overall }}\right)$ :

$k_{d, \text { overall }} C_{\text {overall }} V_{\text {overall }}=k_{d, \text { leaf }} C_{\text {leaf }} V_{\text {leaf }}+k_{d, \text { stem }} C_{\text {stem }} V_{\text {stem }}$

where the contributions to mass change from the leaf and stem layers are equal to the products of their respective filtration rate coefficients $\left(k_{d, \text { leaf }}\right.$ and $k_{d, \text { stem }}$ ), concentrations ( $C_{\text {leaf }}$ and $\left.C_{\text {stem }}\right)$ and volumes ( $V_{\text {leaf }}$ and $\left.V_{\text {stem }}\right)$. Rearranging:

$k_{d, \text { overall }}=\frac{k_{d, \text { leaf }} C_{\text {leaf }} V_{\text {leaf }}+k_{d, \text { stem }} C_{\text {stem }} V_{\text {stem }}}{C_{\text {overall }} V_{\text {overall }}}$

Denoting $T=V_{\text {stem }} / V_{\text {leaf }}$ and $f=k_{d, \text { stem }} / k_{d, \text { leaf }}$ and substituting gives:

$k_{d, \text { overall }}=\frac{\left(C_{\text {leaf }}+T f C_{\text {stem }}\right) k_{d, \text { leaf }}}{(1+T) C_{\text {overall }}}$

Mass balance dictates that the overall water column concentration $\left(C_{\text {overall }}\right)$ comprises contributions from the leaf $\left(C_{\text {leaf }}\right)$ and stem $\left(C_{\text {stem }}\right)$ layers:

$C_{\text {overall }}=\frac{C_{\text {leaf }} V_{\text {leaf }}+C_{\text {stem }} V_{\text {stem }}}{V_{\text {leaf }}+V_{\text {stem }}}$

4.3. Substituting $V_{\text {stem }}=T V_{\text {leaf }}$ and cancelling $V_{\text {leaf }}$ gives

$C_{\text {overall }}=\frac{C_{\text {leaf }}+T C_{\text {stem }}}{1+T}$ 
Substituting the expression for $C_{\text {overall }}$ into the expression for $k_{d, \text { overall }}$ and cancelling terms:

$k_{d, \text { overall }}=\frac{\left(C_{\text {leaf }}+T f C_{\text {stem }}\right) k_{d, \text { leaf }}}{C_{\text {leaf }}+T C_{\text {stem }}}$

In the flume, $C_{\text {leaf }}$ and $C_{\text {stem }}$ will change with advection, dispersion and settling:

$\frac{\partial C_{\text {leaf }}}{\partial t}=-k_{\text {grav }} C_{\text {leaf }}-v \frac{\partial C_{\text {leaf }}}{\partial x}+D \frac{\partial^{2} C_{\text {leaf }}}{\partial x^{2}}$

$\frac{\partial C_{\text {stem }}}{\partial t}=+k_{\text {grav }} C_{\text {leaf }}-v \frac{\partial C_{\text {stem }}}{\partial x}+D \frac{\partial C_{\text {stem }}^{2}}{\partial x^{2}}$

where velocity $(v)$, dispersion $(D)$, and the settling rate coefficient $\left(k_{\text {grav }}\right)$ are for the sake of parsimony considered equivalent in the leaf and stem layers. At steady state, the above temporal derivates are zero. Furthermore, since $D k_{\text {grav }} / v^{2} \ll 1$ for our experiments (Table SI1-4), the dispersive flux has negligible impact on the breakthrough concentration in which case the equations simplify to:

$v \frac{d C_{\text {leaf }}}{d x}=-k_{\text {grav }} C_{\text {leaf }}$

$v \frac{d C_{\text {stem }}}{d x}=+k_{\text {grav }} C_{\text {leaf }}$

Separating and integrating yields for $C_{\text {leaf }}$, and denoting $\lambda=k_{\text {grav }} / v$ :

$\frac{C_{\text {leaf }}}{C_{0}}=\exp (-\lambda L)$

where $L$ is a location of interest. Separating and integrating after substituting the expression for $C_{\text {leaf }}$ yields for $C_{\text {stem }}$ :

$\frac{C_{\text {stem }}}{C_{0}}=1+L \frac{\lambda}{T} \exp (\lambda L)$

Substituting the expressions for $C_{\text {leaf }}$ and $C_{\text {stem }}$ into the expression for $k_{\text {d,overall }}$ yields:

$k_{d, \text { overall }}=k_{d, \text { leaf }} \frac{\exp (-\lambda L)+T f\left[1+L \frac{\lambda}{T} \exp (\lambda L)\right]}{\exp (-\lambda L)+T\left[1+L \frac{\lambda}{T} \exp (\lambda L)\right]}$

In the equation immediately above, the first terms in the numerator and denominator (with negative exponents) decrease with increasing distance $(L)$, whereas the second terms in the numerator and denominator (with positive exponents) increase with distance. The denominator increases faster than the numerator as $L$ increases (since $f<1$ ), such that $k_{d, \text { overall }}$ decreases with increasing transport distance due to the influence of gravity $\left(k_{\text {grav }}\right)$ in $\lambda$. For $\lambda L \gg 1, k_{d, \text { overall }} \rightarrow k_{d, \text { stem }}$, as expected (all the colloids eventually sink from the top layer to the bottom layer under the influence of gravity).

The value of $k_{d, \text { overall }}$ was calculated for our experimental system at the medium velocity $(0.025 \mathrm{~m} / \mathrm{s})$, where $k_{\text {grav }}\left(6.54 \times 10^{-5} / \mathrm{s}\right)$ was upscaled from $\eta_{G}$ using Eqs. (2) and (3). Prior to upscaling, $\eta_{G}(4.84 \times$ $10^{-6}$ ) was doubled to reflect the fact that colloid injection occurred on both the upper and lower sides of the collector in Traj-Hap, whereas colloids were introduced only above the flume bottom in the experiments.

As noted just above, the calculations confirm that $C_{\text {leaf }}$ decreases and $C_{\text {stem }}$ increases across the 10-m transport distance due to the influence of gravity (Fig. 6a). As a result, the value of $k_{d \text {,overall }}$ will decrease with increased transport distance (Fig. $6 \mathrm{~b}$ ) towards $k_{d, \text { stem }}$. The magnitude will decrease with decreasing $f$ (Fig. 6b), but the rate of decrease with increased transport distance is equivalent regardless of $f$ (Fig. 6b). Whereas the calculated decrease in $k_{d, \text { overall }}$ due to gravity with increased transport distance qualitatively agrees with the experimentally-
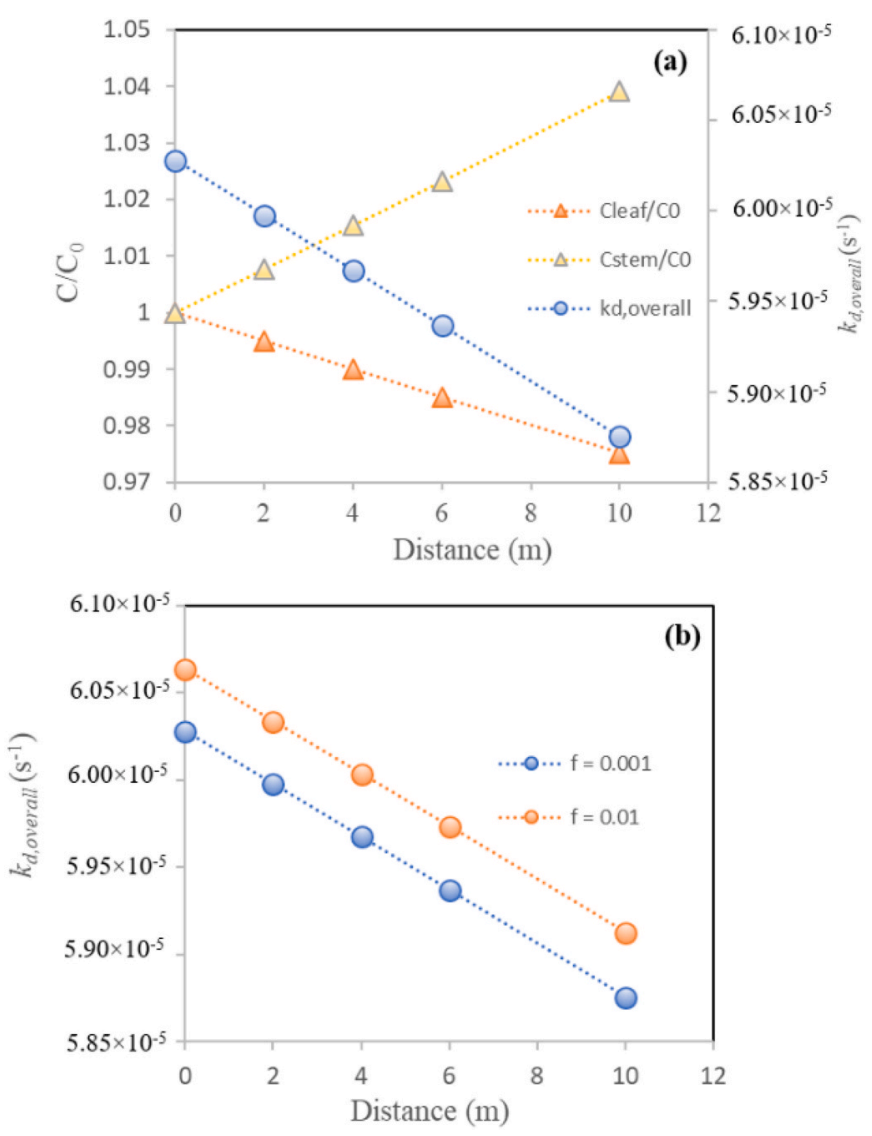

Fig. 6. (a) Calculated colloid concentration in the leaf and stem layers (left axis) and $k_{d, \text { overall }}$ (right axis) as a function of travel distance for $k_{d, \text { stem }} / k_{d \text {,leaf }}=f$ $=0.001$. (b) Variation of $k_{d \text {,overall }}$ with distance as a function of $f$.

observed trend, the magnitude $(2.5 \%)$ of the decrease is too small to explain the observed $k_{d, \text { overall }}$ decrease according to a power law.

Since measured parameters and gravity cannot explain the observed $k_{d}$ decrease with increased transport distance, it is possible that the mechanism for this decrease is similar to that found for porous media. For example, Messina et al. (2016) suggested that the removal of colloids through direct interception was greater in the forepart of a series of spherical collectors relative to subsequent collectors. However, the simulated modest decrease could not match the experimentally-observed power law decrease. Johnson (2020) demonstrated that larger decreases could be simulated under the assumption that subpopulations of fast- and slow-attaching colloids are produced via incomplete pore-scale mixing during transport in granular media. Whether the mechanism is more akin to those proposed for granular media, or to those proposed for vortices (Purich, 2006) or turbulent flow (Nepf, 2012) remains to be determined.

\section{Conclusions}

In this paper, the retention and transport of colloids in submerged synthetic vegetation were studied using indoor large-scale flume experiments under various conditions. The colloid deposition rate coefficient, $k_{d}$, was maximal at the intermediate velocity, and it was shown through mechanistic trajectory simulations that the gravity and interception components of the collector efficiency were also maximal at the intermediate velocity, likely contributing to the experimentallyobserved trend. The value of $k_{d}$ decreased following an approximate power law behavior with increasing transport distance. While calculations based on mechanistic trajectory simulations demonstrated that gravity contributed to this outcome, the impact of gravity was insuffi- 
cient to explain the experimental trend, suggesting that mechanisms governing such trends in granular media could also apply to submerged vegetation.

The practical implications of the findings include the fact that colloid removal by vegetation can be a non-monotonic function of fluid velocity, such that decreased removal along with increased erosion under higher fluid velocity conditions can undermine the filtration function of submerged vegetation. Furthermore, the value of $k_{d}$ determined at small scales potentially greatly over-predicts the magnitude of $k_{d}$ (and removal) operating at larger scales, i.e., the rate of removal cannot be extrapolated linearly as a function of distance.

\section{Credit author statement}

Congrong Yu: Conceptualization, Methodology, Software, WritingReviewing and Editing. Peiyi Duan: Experiment conducting, Data collecting, Writing-Original draft preparation. D. A. Barry: Supervision, Writing- Reviewing and Editing. William P. Johnson: modeling and in interpreting the experimental results. Li Chen and Zhongbo Yu: Visualization, Investigation. Yufeng Sun and Ying Li: Experiment conducting, Validation.

\section{Declaration of competing interest}

The authors declare that they have no known competing financial interests or personal relationships that could have appeared to influence the work reported in this paper.

\section{Acknowledgements}

This work was supported by the National Key Research and Development Program of China (2018YFC1508200), the National Natural Science Foundation of China (Grant No. 51509069, 41830752), the Belt and Road Special Foundation of the State Key Laboratory of HydrologyWater Resources and Hydraulic Engineering (Grant No. 2020491711), the Shuangchuang Fund of Jiangsu Province in China, and the Fundamental Research Funds for the Central Universities of China (Grant No. 2019B10814). WPJ's contributions were supported by the U.S. National Science Foundation under grant number HS-1951676. Any opinions, findings, and conclusions expressed in this material are those of the authors and do not necessarily reflect the views of the National Science Foundation.

\section{Appendix A. Supplementary data}

Supplementary data to this article can be found online at https://doi. org/10.1016/j.chemosphere.2021.132197.

\section{References}

Albarran, N., Degueldre, C., Missana, T., Alonso, U., Garcia-Gutierrez, M., Lopez, T., 2014. Size distribution analysis of colloid generated from compacted bentonite in low ionic strength aqueous solutions. Appl. Clay Sci. 95, 284-293. https://doi.org/ 10.1016/j.clay.2014.04.025.

Barry, D.A., Sander, G.C., Jomaa, S., Yeghiazarian, L., Steenhuis, T.S., Selker, J.S., 2013. Solute and sediment transport at laboratory and field scale. Contributions of J.-Y. Parlange. Water Resources Research 49 (10), 6111-6136. https://doi.org/10.1002/ wrcr.20510.

Bin, G., Cao, X., Dong, Y., Luo, Y., Ma, L.Q., 2011. Colloid deposition and release in soils and their association with heavy metals. Crit. Rev. Environ. Sci. Technol. 41 (4), 336-372. https://doi.org/10.1080/10643380902871464.

Bradford, S.A., Simunek, J., Bettahar, M., van Genuchten, M.Th, Yates, S.R., 2003. Modeling colloid attachment, straining, and exclusion in saturated porous media. Environ. Sci. Technol. 37 (10), 2242-2250. https://doi.org/10.1021/es025899u.

Bradford, S.A., Torkzaban, S., Shapiro, A., 2013. A theoretical analysis of colloid attachment and straining in chemically heterogeneous porous media. Langmuir 29 (23), 6944-6952. https://doi.org/10.1021/la4011357.

Chatterjee, J., Abdulkareem, S., Gupta, S.K., 2010. Estimation of colloidal deposition from heterogeneous populations. Water Res. 44 (11), 3365-3374. https://doi.org/ 10.1016/j.watres.2010.03.025.
Chatterjee, J., Pratap, S., Abdulkareem, S., 2011. Dual-deposition rates in colloid filtration caused by coupled heterogeneities in a colloidal population. J. Colloid Interface Sci. 356 (1), 362-368. https://doi.org/10.1016/j.jcis.2010.12.029.

Chen, H., Gao, B., Yang, L.Y., Ma, L.Q., 2015. Montmorillonite enhanced ciprofloxacin transport in saturated porous media with sorbed ciprofloxacin showing antibiotic activity. J. Contam. Hydrol. 173, 1-7. https://doi.org/10.1016/j. jconhyd.2014.11.010.

Davies, C.M., Ferguson, C.M., Kaucner, C., Krogh, M., Altavilla, N., Deere, D.A., Ashbolt, N.J., 2004. Dispersion and transport of cryptosporidium oocysts from fecal pats under simulated rainfall events. Appl. Environ. Microbiol. 70 (2), 1151-1159. https://doi.org/10.1128/aem.70.2.1151-1159.2004.

Derjaguin, B., Landau, L., 1993. Theory of the stability of strongly charged lyophobic sols and of the adhesion of strongly charged particles in solutions of electrolytes. Prog. Surf. Sci. 43 (1-4), 30-59. https://doi.org/10.1016/0079-6816(93)90013-L.

Foppen, J.W., van Herwerden, M., Schijven, J., 2007. Transport of Escherichia Coli in saturated porous media: dual mode deposition and intra-population heterogeneity. Water Res. 41 (8), 1743-1753. https://doi.org/10.1016/j.watres.2006.12.041.

Gao, B., Saiers, J.E., Ryan, J.N., 2004. Deposition and mobilization of clay colloids in unsaturated porous media. Water Resour. Res. 40 (8), W08602. https://doi.org/ 10.1029/2004wr003189.

Gregory, J., 1981. Approximate expressions for retarded van der Waals interaction. J. Colloid Interface Sci. 83 (1), 138-145. https://doi.org/10.1016/0021-9797(81) 90018-7.

Hickey, M.B.C., Doran, B., 2004. A review of the efficiency of buffer strips for the maintenance and enhancement of riparian ecosystems. Water Qual. Res. J. Can. 39 (3), 311-317. https://doi.org/10.2166/warj.2004.042.

Jin, G., Jiang, Q., Tang, H., Li, L., Barry, D.A., 2018. Density effects on nanoparticle transport in the hyporheic zone. Adv. Water Resour. 121, 406-418. https://doi.org/ 10.1016/j.advwatres.2018.09.004.

Jin, G., Zhang, Z., Tang, H., Yang, X., Li, L., Barry, D.A., 2019. Colloid transport and distribution in the hyporheic zone. Hydrol. Process. 33 (6), 932-944. https://doi. org/10.1002/hyp.13375.

Johnson, W.P., 2020. Quantitative linking of nanoscale interactions to continuum-scale nanoparticle and microplastic transport in environmental granular media. Environ. Sci. Technol. 54 (13), 8032-8042. https://doi.org/10.1021/acs.est.0c01172.

Johnson, W.P., Hilpert, M., 2013. Upscaling colloid transport and retention under unfavorable conditions. Water Resour. Res. 49, 1-14. https://doi.org/10.1002/ wrcr.20433.

Koelsch, R.K., Lorimor, J.C., Mankin, K.R., 2006. Vegetative treatment systems for management of open lot runoff: review of literature. Appl. Eng. Agric. 22 (1), 141-153 last accessed 7 July, 2021. https://digitalcommons.unl.edu/cgi/viewcont ent.cgi? article $=1004 \&$ context=biosysengfacpub.

Kretzschmar, R., Barmettler, K., Grolimund, D., Yan, Y., Borkovec, M., Sticher, H., 1997. Experimental determination of colloid deposition rates and collision efficiencies in natural porous media. Water Resour. Res. 33 (5), 1129-1137. https://doi.org/ 10.1029/97wr00298.

Li, X., Scheibe, T.D., Johnson, W.P., 2004. Apparent decreases in colloid removal rate coefficients with distance of transport under unfavorable deposition conditions: a general phenomenon. Environ. Sci. Technol. 38 (21), 5616-5625. https://doi.org/ $10.1021 / \mathrm{es} 049154 \mathrm{v}$.

Lin, S., Wiesner, M.R., 2012. Paradox of stability of nanoparticles at very low ionic strength. Langmuir 28 (30), 11032-11041. https://doi.org/10.1021/la3016589.

Magette, W.L., Brinsfield, R.B., Palmer, R.E., Wood, J.D., 1989. Nutrient and sediment removal by vegetated filter strips. Trans. ASAE (Am. Soc. Agric. Eng.) 32 (2), 663-667 last accessed 7 July 2021. https://researchrepository.ucd.ie/handle/101 $97 / 4157$.

Messina, F., Tosco, T., Sethi, R., 2016. On the failure of upscaling the single-collector efficiency to the transport of colloids in an array of collectors. Water Resour. Res. 52 (7), 5492-5505. https://doi.org/10.1002/2016wr018592.

Molnar, I.L., Johnson, W.P., Gerhard, J.I., Willson, C.S., O'Carroll, D.M., 2015. Predicting colloid transport through saturated porous media: a critical review. Water Resour. Res. 51 (9), 6804-6845. https://doi.org/10.1002/2015wr017318.

Nelson, K.E., Ginn, T.R., 2011. New collector efficiency equation for colloid filtration in both natural and engineered flow conditions. Water Resour. Res. 47, W05543. https://doi.org/10.1029/2010WR009587.

Nepf, H.M., 2012. Flow and transport in regions with aquatic vegetation. Annu. Rev. Fluid Mech. 44 (1), 123-142. https://doi.org/10.1146/annurev-fluid-120710101048.

Nir, S., Andersen, M., 1977. Van der Waals interactions between cell surfaces. J. Membr. Biol. 31 (1), 1-18. https://doi.org/10.1007/BF01869396.

Olilo, C.O., Onyando, J.O., Moturi, W.N., Muia, A.W., Ombui, P., Shivoga, W.A., Roegner, A.F., 2016. Effect of vegetated filter strips on transport and deposition rates of Escherichia Coli in overland flow in the eastern escarpments of the Mau forest, Njoro River watershed, Kenya. Energy Ecol. Environ. 1 (3), 157-182. https://doi. org/10.1007/s40974-016-0006-y.

Palmer, M.R., Nepf, H.M., Pettersson, T.J.R., 2004. Observations of particle capture on a cylindrical collector: implications for particle accumulation and removal in aquatic systems. Limnol. Oceanogr. 49 (1), 76-85. https://doi.org/10.4319/ lo.2004.49.1.0076.

Phenrat, T., Song, J.E., Cisneros, C.M., Schoenfelder, D.P., Tilton, R.D., Lowry, G.V., 2010. Estimating attachment of nano- and submicrometer-particles coated with organic macromolecules in porous media: Development of an empirical model. Environ. Sci. Technol. 44 (12), 4531-4538. https://doi.org/10.1021/es903959c.

Reichenberger, S., Bach, M., Skitschak, A., Frede, H.G., 2007. Mitigation strategies to reduce pesticide inputs into ground- and surface water and their effectiveness; A 
review. Sci. Total Environ. 384 (1-3), 1-35. https://doi.org/10.1016/j. scitotenv.2007.04.046.

Saiers, J.E., Ryan, J.N., 2005. Colloid deposition on non-ideal porous media: the influences of collector shape and roughness on the single-collector efficiency. Geophys. Res. Lett. 32 (21), L21406. https://doi.org/10.1029/2005g1024343.

Schijven, J.F., Šimůnek, J., 2002. Kinetic modeling of virus transport at the field scale. J. Contam. Hydrol. 55 (1-2), 113-135. https://doi.org/10.1016/s0169-7722(01) 00188-7.

Syngouna, V.I., Chrysikopoulos, C.V., 2013. Cotransport of clay colloids and viruses in water saturated porous media. Colloid. Surface. Physicochem. Eng. Aspect. 416, 56-65. https://doi.org/10.1016/j.colsurfa.2012.10.018.

Syversen, N., Bechamann, M., 2004. Vegetative buffer zones as pesticide filters for simulated surface runoff. Ecol. Eng. 2 (3), 175-184. https://doi.org/10.1016/j ecoleng.2004.05.002.

Tomer, M.D., James, D.E., Isenhart, T.M., 2003. Optimizing the placement of riparian practices in a watershed using terrain analysis. J. Soil Water Conserv. 58 (4), 198-206 last accessed 7 July 2021. https://www.jswconline.org/content/58/4/198.

Tong, M., Johnson, W.P., 2007. Colloid population heterogeneity drives hyperexponential deviation from classic filtration theory. Environ. Sci. Technol. 41 (2), 493-499. https://doi.org/10.1021/es061202j.

Tufenkji, N., Elimelech, M., 2005. Breakdown of colloid filtration theory: role of the secondary energy minimum and surface charge heterogeneities. Langmuir 21 (3), 841-852. https://doi.org/10.1021/la048102g.

Tufenkji, N., Redman, J.A., Elimelech, M., 2003. Interpreting deposition patterns of microbial particles in laboratory-scale column experiments. Environ. Sci. Technol. 37 (3), 616-623. https://doi.org/10.1021/es025871i.

Verwey, E.J.W., 1947. Theory of the stability of lyophobic colloids. J. Phys. Colloid Chem. 51 (3), 631-636. https://doi.org/10.1021/j150453a001.

Wang, L.M., Wang, Y.H., 2008. Research and application advances on vegetative filter strip. Chin. J. Appl. Ecol. 19 (9), 2074 last accessed 7 July 2021. http://en.cnki.com. cn/Article_en/CJFDTotal-YYSB200809033.htm.
Wang, D., Ge, L., He, J., Zhang, W., Jaisi, D.P., Zhou, D., 2014. Hyperexponential and nonmonotonic retention of polyvinylpyrrolidone-coated silver nanoparticles in an Ultisol. J. Contam. Hydrol. 164, 35-48. https://doi.org/10.1016/j. jconhyd.2014.05.007.

Wang, Y., Yin, X., Sun, H., Wang, C., 2016. Transport of vanadium (V) in saturated porous media: effects of $\mathrm{pH}$, ionic-strength and clay mineral. Chem. Speciat. Bioavailab. 28 (1-4), 7-12. https://doi.org/10.1080/09542299.2015.1133238.

Wood, J.A., Rehmann, L., 2014. Geometric effects on non-DLVO forces: relevance for nanosystems. Langmuir 30 (16), 4623-4632. https://doi.org/10.1021/la500664c.

Wu, L., Gao, B., Munoz-Carpena, R., 2011. Experimental analysis of colloid capture by a cylindrical collector in laminar overland flow. Environ. Sci. Technol. 45 (18), 7777-7784. https://doi.org/10.1021/es201578n.

Wu, L., Gao, B., Munoz-Carpena, R., Pachepsky, Y.A., 2012. Single collector attachment efficiency of colloid capture by a cylindrical collector in laminar overland flow. Environ. Sci. Technol. 46 (16), 8878-8886. https://doi.org/10.1021/es301365f.

Wu, L., Munoz-Carpena, R., Gao, B., Yang, W., Pachepsky, Y.A., 2014. Colloid filtration in surface dense vegetation: experimental results and theoretical predictions. Environ. Sci. Technol. 48 (7), 3883-3890. https://doi.org/10.1021/es404603g.

Yu, C., Gao, B., Munoz-Carpena, R., 2012. Effect of dense vegetation on colloid transport and removal in surface runoff. J. Hydrol. 434, 1-6. https://doi.org/10.1016/j. jhydrol.2012.02.042.

Yu, C.R., Munoz-Carpena, R., Gao, B., Perez-Ovilla, O., 2013. Effects of ionic strength, particle size, flow rate, and vegetation type on colloid transport through a dense vegetation saturated soil system: experiments and modeling. J. Hydrol. 499, 316-323. https://doi.org/10.1016/j.jhydrol.2013.07.004.

Yu, C.R., Duan, P.Y., Yu, Z.B., Gao, B., 2019. Experimental and model investigations of vegetative filter strips for contaminant removal: a review. Ecol. Eng. 126, 25-36. https://doi.org/10.1016/j.ecoleng.2018.10.020.

Yu, C., Guo, X., Gao, X., Yu, Z., Jiang, J., 2020. Transport of graphene quantum dots (GQDs) in saturated porous media. Colloid. Surface. Physicochem. Eng. Aspect. 589, 124418. https://doi.org/10.1016/j.colsurfa.2020.124418. 